\title{
Skill and art in an intolerant world: a brief commentary on the article by Paiva et al.
}

I thank the Editors of CSP for the opportunity to read and comment briefly on the excellent article by Paiva et al., The Current State of Play of Research on the Social, Political and Legal Dimensions of HIV (p. 477-86). Commentators often cite limited space as an acceptable excuse for overly brief commentary. Note, however, that their critical review covers a vast set of papers and debates from "track D" of the 20th International AIDS Conference, held in Melbourne, Australia, in 2014.

I agree with the authors that we live in an intolerant and aggressive world, not only for various minorities, but also for groups that constitute the majority in various contexts, like women and young people. The wide range of social and cultural groups that experience discrimination (symbolic and physical violence, even to the point of extermination) prevents me from subscribing to the opinion of authors like Steven Pinker 1 in what he calls The Better Angels of our Nature. For an epidemiologist like me who works in Latin America and analyzes short historical series (i.e., decades, when historical time is measured in centuries), the guardian angels of non-violence are unfortunately not among us. I would like to share the author's optimism for long-term perspectives, but I see it as the result of inconsistency in statistics that cut across widely diverse centuries and cultures, measured by indicators that cannot be conceptualized as such. I witness the opposite in my daily work: aggression against drug users (the population I work with), homophobic and racial violence, and abuse of women. For the so-called "key populations" (using the World Health Organization's terminology) 2, I fail to see progress (although in some contexts, such as Brazil, there have been timid steps against racism in some legal arenas, but back-sliding in relation to homophobia).

The authors' discussion on the successive terminological changes for what are now called "key populations" reminds me of Susan Sontag's essays on illnesses and their deadly metaphors. Beyond the value of Sontag's work for the social sciences and literature, she established a profound dialogue between the experience of overcoming her own illness and the illness and death of some of her closest friends due to AIDS (in 1978 and 1988, respectively). As shown by the current article's authors, prejudice and stigma do not die, but are reconfigured (and hopefully can be mitigated).

I reserve my final quota of space to lament the degradation of my own field, epidemiology, which has been losing what Camoens called "skill and art", all too often turning into a collection of platitudes. Suffice it to recall that the article by Victora et al. ${ }^{3}$ on the urgency of integrated evaluation of public health measures (rather than mechanical transposition of findings from clinical trials) was published in 2004 (!). And that Myron Cohen, the leader of research on "treatment as prevention" (TasP), problematized the desirable but incredibly simplistic idea of eliminating HIV through standard medical interventions 4 . I endorse the current authors' hope in so-called "combined interventions" (obviously depending on what such combinations include). And I second their criticism against the dismantling of harm reduction programs around the world in favor of a purported silver bullet (whether PrEP or another unilateral intervention), which inhabits the imagination of some, but not the world in which we live. 
As a professor of students in epidemiology and collective health, I truly wish my young colleagues would read the founding authors of their field and learn from accumulated experience, aware that it was no coincidence when Ulysses ordered his crew to bind him to the ship's mast when they sailed past Capri (the isle of the sirens' enticing but deadly song).

Francisco I. Bastos

Instituto de Comunicação e Informação Científica e Tecnológica em Saúde, Fundação Oswaldo Cruz, Rio de Janeiro, Brasil.

francisco.inacio.bastos@hotmail.com

1. Pinker S. The better angels of our nature: why violence has declined. New York: Viking; 2011.

2. World Health Organization. Consolidated guidelines on HIV prevention, diagnosis, treatment and care for key populations. Geneva: World Health Organization; 2014.

3. Victora CG, Habicht JP, Bryce J. Evidence-based public health: moving beyond randomized trials. Am J Public Health 2004; 94:400-5.

4. Cohen MS, Dye C, Fraser C, Miller WC, Powers KA, Williams BG. HIV treatment as prevention: debate and commentary - will early infection compromise treatment-as-prevention strategies? PloS Med 2012; 9:e1001232. 